\title{
Safe zone for minimally invasive calcaneal osteotomy: an MRI study
}

\author{
Vasantha Kumar Ramsingh, George Hourston, Sriram SRinivasan, Suresh Annamalai
}

From the Department of Trauma and Orthopaedics, Royal Gwent Hospital, Cardiff Road, Newport, UK,

Hindfoot deformities are often surgically corrected with calcaneal osteotomy. These are increasingly performed via a minimally invasive approach. Identifying a neurovascular "safe zone" for this approach is important in reducing iatrogenic injury. We aimed to identify a safe zone for minimally invasive calcaneal osteotomy without neurovascular injury.

Three individuals independently assessed 100 consecutive magnetic resonance imaging ankle studies. The distance of the medial neurovascular bundle from the level of the centre of the Achilles tendon insertion was measured. The points measured were centralised in three planes (axial, sagittal and coronal). The three sets of observations were statistically analysed with confidence intervals and intraclass correlation coefficient was calculated.

The mean distance measured by the three observers were $22.91 \mathrm{~mm}$ (range 18.2-28.5 mm); $22.81 \mathrm{~mm}$ (range 18.7-26.7 $\mathrm{mm}$ ); and $23.41 \mathrm{~mm}$ (range 19.2$28.4 \mathrm{~mm}$ ); overall mean $23.0 \mathrm{~mm}$. The mean interobserver variation was $1.1 \mathrm{~mm} .95 \%$ confidence interval for observer 1 ranges from 22.45-23.25 $\mathrm{mm}$, observer 2 ranges from $22.52-23.1 \mathrm{~mm}$ and observer 3 ranges from $22.97-23.65 \mathrm{~mm}$. Overall $95 \%$ confidence interval ranges from $22.8-23.2 \mathrm{~mm}$. Intraclass correlation coefficient for inter-observer reliability is 0.7 , indicating strong agreement between the observers.

This radiological study suggests an anatomical "safe zone" for minimally invasive medial calcaneal osteotomy is at least $18 \mathrm{~mm}$ (mean: $23 \mathrm{~mm}$ ) from the level of insertion of the Achilles tendon. Individual variation between patients must be taken in to consideration during preoperative planning.

No benefits or funds were received in support of this study. None of the authors have a conflict of interest.
Keywords: Calcaneal osteotomy; safe zone; minimally invasive.

\section{INTRODUCTION}

Calcaneal osteotomy is a commonly performed procedure for deformities of the foot and ankle (1). Gleich first described the medical closing wedge calcaneal osteotomy in 1893 (1-4). Such procedures are now commonplace in the management of pes planovalgus deformities, rear foot varus deformities, tibialis posterior tendon dysfunction and posttraumatic deformities $(5,6)$. These osteotomies have traditionally been undertaken via a lateral approach, which is associated with such complications as

\footnotetext{
Vasantha Kumar Ramsingh ${ }^{1}$,

George Hourston²,

Sriram Srinivasan ${ }^{2}$,

- Suresh Annamalai ${ }^{3}$

${ }^{1}$ Department of Trauma and Orthopaedics, Royal Gwent Hospital, Cardiff Road, Newport, UK.

${ }^{2}$ Department of Trauma and Orthopaedics, James Paget University Hospitals NHS Foundation Trust, UK.

${ }^{3}$ Department of Trauma and Orthopaedics, Norfolk and Norwich University Hospitals NHS Foundation, Trust, UK

Correspondence : Dr George JM Hourston MA (Cantab) MB BChir PGCert, Core Surgical Trainee, Department of Trauma and Orthopaedics, James Paget University Hospitals NHS Foundation Trust, UK, NR31 6LA.

Email : gjmh3@cam.ac.uk

- 2021, Acta Orthopædica Belgica.
} 
wound dehiscence, sural neuropraxia, sural neuritis, delayed union, non-union, infection, and injury of the medial neurovascular structures $(5,6)$. A minimally invasive approach has therefore been developed in order to obviate these complications. In this percutaneous technique the entire procedure is performed through four small stab incisions thereby avoiding the need for a larger open incision which would be more prone to dehiscence and fibrosis (7). This reduces the risk of nerve-related symptoms, and when performed correctly, completely avoids the major neurovascular structures (7-9).

The present study utilised pre-operative magnetic resonance imaging (MRI) of patients presenting with foot and ankle complaints in an attempt to identify an anatomical "safe zone" in which minimally invasive percutaneous calcaneal osteotomy can be performed.

\section{MATERIALS AND METHODS}

One hundred consecutive MRI ankle scans were independently assessed by three individual observers using stacked images of coronal, sagittal and axial sections on PACS (picture archive and communication system) on a single monitor. The distance between the medial neurovascular bundle

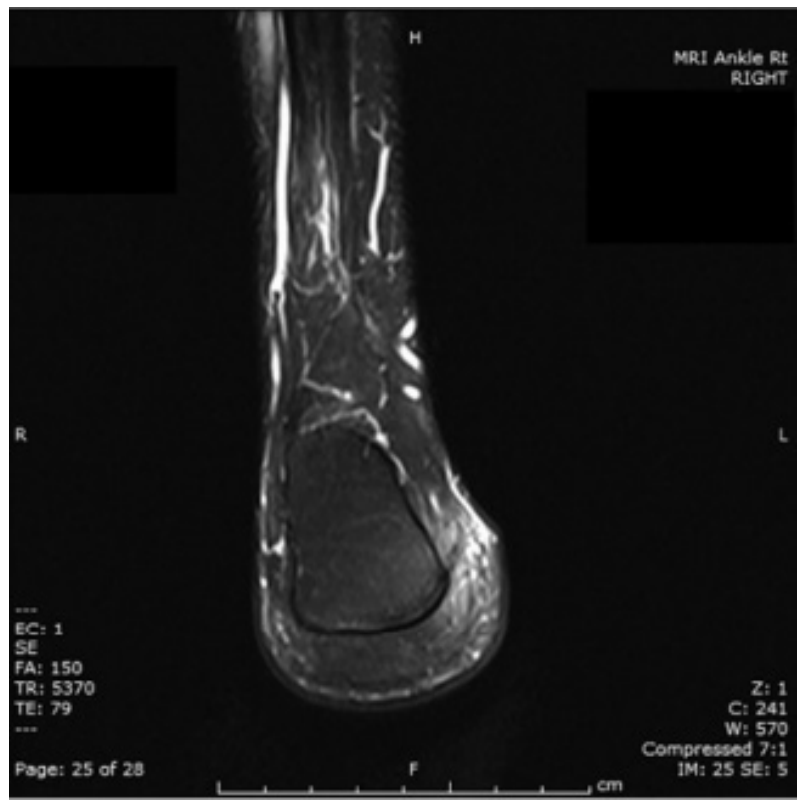

Figure 1. - Coronal section.

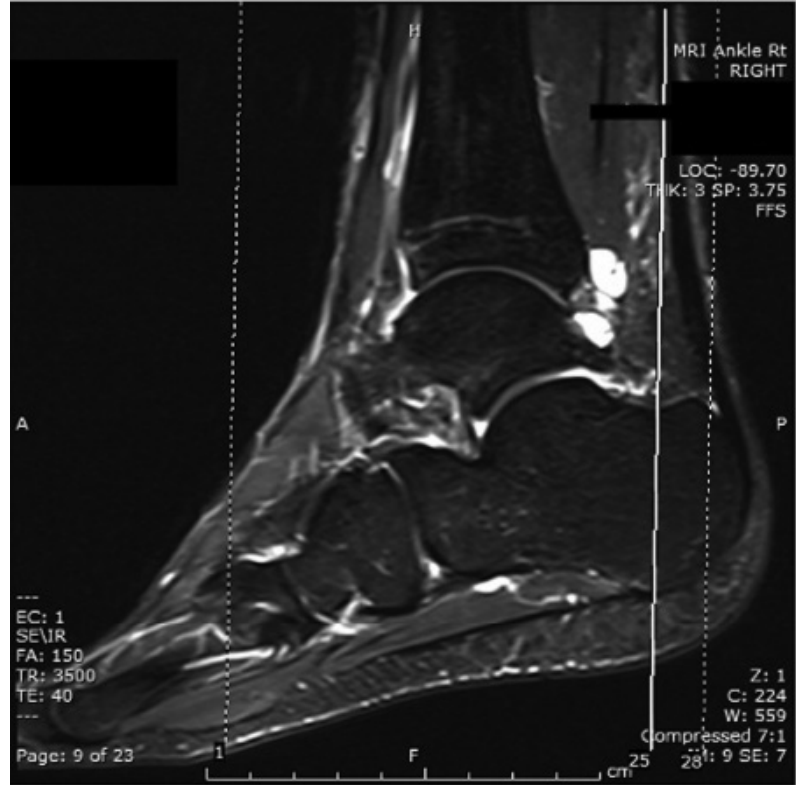

Figure 2. - Sagittal section.

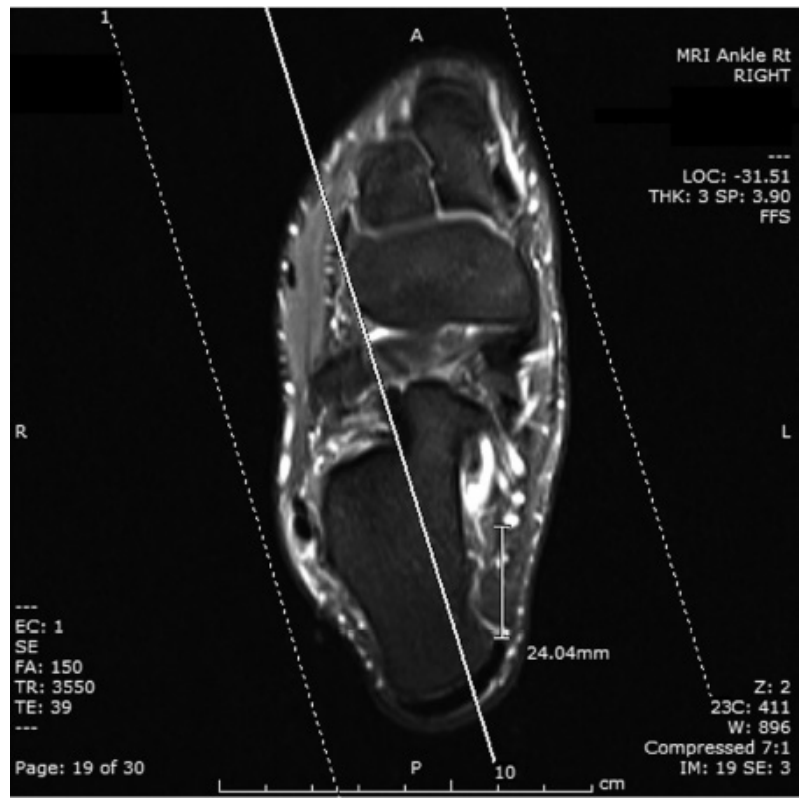

Figure 3. - Axial section.

and a fixed bony prominence at the Achilles tendon insertion was measured. The Achilles tendon insertion was identified on coronal sections (figure 1), then the sagittal section at the midline of the tendon was obtained (figure 2). The distance from the most proximal insertion point of the Achilles tendon to 
the neurovascular bundle was then measured on the axial view (figure 3 ). Inter-observer variability was statistically analysed using confidence interval and intra-class correlation coefficient.

\section{RESULTS}

The mean distance measured by observer 1 was $22.91 \mathrm{~mm}(18.2-28.5 \mathrm{~mm})$, observer 2 was 22.81 $\mathrm{mm}(18.7-26.7 \mathrm{~mm})$ and observer 3 was $23.41 \mathrm{~mm}$ $(19.2-28.4 \mathrm{~mm})$. The overall mean for the three observers was $23.0 \mathrm{~mm}$ (Table 1). The mean interobserver variation between observer 1 and observer 2 was $1.1 \mathrm{~mm}(0 \mathrm{~mm}-3.7 \mathrm{~mm})$, between observer 1 and observer 3 was $1.2 \mathrm{~mm}(0.1 \mathrm{~mm}-5.5 \mathrm{~mm})$ and between observer 2 and observer 3 was $0.96 \mathrm{~mm}$ $(0.1 \mathrm{~mm}-6 \mathrm{~mm})$. The over all mean inter-observer variations was $1.1 \mathrm{~mm}$. 95\% confidence interval for observer 1 ranges from $22.45-23.25 \mathrm{~mm}$, observer 2 ranges from $22.52-23.1 \mathrm{~mm}$ and observer 3 ranges from 22.97-23.65 mm. Over all 95\% confidence interval ranges from 22.8-23.2 $\mathrm{mm}$. Intraclass correlation coefficient (ICC) for inter-observer reliability is 0.7 , this indicates strong agreement between the observers.

The minimum distance measured from the 100 MRI scans by all three observers was $18.2 \mathrm{~mm}$, hence, this study suggests that the "safe zone" on the medial side of the calcaneum for minimally invasive osteotomy is at least $18 \mathrm{~mm}$ (mean $23 \mathrm{~mm}$ ) from the level of Achilles tendon insertion. However, in pre-operative planning, patient anatomical variation must always be considered.

\section{DISCUSSION}

In the present study, we have utilised pre-operative MRI scans of patients undergoing calcaneal

Table 1. - Mean distance measurements

\begin{tabular}{|l|c|c|c|}
\hline & Observer 1 & Observer 2 & Observer 3 \\
\hline $\begin{array}{l}\text { Distance Range } \\
\text { (mm) }\end{array}$ & $18.2-28.5$ & $18.7-6.7$ & $19.2-28.4$ \\
\hline $\begin{array}{l}\text { Mean Distance } \\
\text { (mm) }\end{array}$ & 22.9 & 22.81 & 23.41 \\
\hline
\end{tabular}

Overall Mean Distance: $23.0 \mathrm{~mm}$ osteotomy to assess the relation of the medial neurovascular structures to the most proximal portion of the insertion of the Achilles tendon. This study suggests that there may indeed be a "safe zone" for minimally invasive calcaneal osteotomy. To our knowledge there are no studies utilizing MRI to assess the medial neurovascular structures around the calcaneum. Our statistical analysis showed good inter-observer reliability between the three observers, and that calcaneal osteotomy performed within $18 \mathrm{~mm}$ of the Achilles tendon insertion is likely to be safe.

Minimally invasive calcaneal osteotomy is performed via four stab incisions around the heel; two lateral, and two medial. A saw is then inserted close to the calcaneal surface through these incisions, its position confirmed by fluoroscopic imaging, and the osteotomy is then performed (10).

Anatomical structures including the medial and lateral plantar nerves, the medial calcaneal nerve, posterior tibial nerve and sural nerve and blood vessels are susceptible to iatrogenic injury during percutaneous calcaneal osteotomy. Greene et al noted that on average four and a minimum of two anatomic structures crossed the osteotomy site in their study of 22 cadaveric limbs after open calcaneal osteotomy (11). These structures were mostly branches of the lateral plantar nerve or of the posterior tibial artery.

In another cadaveric study by Didomenico et al, the medial and lateral neurovascular structures after percutaneous calcaneal displacement osteotomy were assessed (12). They suggest that percutaneous calcaneal displacement osteotomy is safe, predictable, and could be associated with fewer postoperative complications when compared with open techniques.

There is extensive anatomical variation of the neurovascular structures medial to the calcaneus. For example the bifurcation of the posterior tibial nerve was noted to be within the tarsal tunnel in $93 \%$ but proximal to the tunnel in $7 \%$ of 68 cadaveric limbs studied by Havel et al. (13). The authors also documented at least nine variant patterns of the course of calcaneal nerve.

Investigating a potential safe zone for percutaneous pin placement in the medial calcaneus, Casey 
et al conducted a study of 33 adult cadaveric feet (14). The authors found a relatively safe area for pin placement avoiding the medial neurovascular bundle posterior to the halfway point from the posteroinferior medial calcaneus to the inferior medial malleolus, and posterior to the point one third along from the posteroinferior medial calcaneus to the navicular tuberosity.

Gamie et al, in a similar study, investigated the medial neurovascular structures in relation to four palpable anatomic landmarks (15). Both studies suggested that the more posterior the pin placement in their respective "safe zones", the less risk of iatrogenic damage to the medial neurovascular structures.

\section{CONCLUSION}

This radiological study suggests that there is an anatomical "safe zone" for minimally invasive medical calcaneal osteotomy between the proximal end of the Achilles tendon calcaneal insertion and the medial neurovasculature. However, individual patient anatomical variation must be considered by the operating surgeon.

\section{REFERENCES}

1. McGlamry's Comprehensive Textbook of Foot and Ankle Surgery (2-Volume Set) - Alan S. Banks, Micheal S. Downey, Dennis E. Martin, Stephen J. Miller • Lippincott Williams \& Wilkins - 2001 - ISBN-10: 0683304712 • ISBN-13: 978-0683304718, 2009 [Internet]. [cited 2020 Oct 5]. Available from: https://journals.sagepub.com/doi/ 10.1177/1938640009339139

2. Koutsogiannis E. Treatment of mobile flat foot by displacement osteotomy of the calcaneus. J Bone Joint Surg Br [Internet]. 1971 Feb 1 [cited 2020 Oct 5]; 53-B(1): 96-100. Available from: https://online.boneandjoint.org.uk/ doi/abs/10.1302/0301-620X.53B1.96

3. Weinfeld SB. Medial slide calcaneal osteotomy. Technique, patient selection, and results. Foot Ankle Clin. 2001; 6(1) : 89-94, vii.
4. Trnka HJ, Easley ME, Myerson MS. The role of calcaneal osteotomies for correction of adult flatfoot. Clin Orthop. 1999; (365): 50-64.

5. Bariteau JT, Blankenhorn BD, Tofte JN, DiGiovanni CW. What is the Role and Limit of Calcaneal Osteotomy in the Cavovarus Foot? Foot Ankle Clin [Internet]. 2013 Dec 1 [cited 2020 Oct 5];18(4):697-714. Available from: http://www.sciencedirect.com/science/article/pii/ S1083751513000727

6. Tennant JN, Carmont M, Phisitkul P. Calcaneus osteotomy. Curr Rev Musculoskelet Med [Internet]. 2014 Sep 4 [cited 2020 Oct 5]; 7(4): 271-6. Available from: https:// www.ncbi.nlm.nih.gov/pmc/articles/PMC4596212/

7. Gutteck N, Zeh A, Wohlrab D, Delank K-S. Comparative Results of Percutaneous Calcaneal Osteotomy in Correction of Hindfoot Deformities. Foot Ankle Int. 2019; 40(3): 27681.

8. Veljkovic A, Symes M, Younger A, Rungprai C, Abbas KZ, Salat P, et al. Neurovascular and Clinical Outcomes of the Percutaneous Endoscopically Assisted Calcaneal Osteotomy (PECO) Technique to Correct Hindfoot Malalignment. Foot Ankle Int. 2019; 40(2): 178-84.

9. Frankel J, Turf RM, Nichols D. Complications of calcaneal osteotomies. Clin Podiatr Med Surg. 1991; 8(2): 409-23.

10. Maffulli N, Easley M, editors. Minimally Invasive Surgery of the Foot and Ankle [Internet]. London: Springer-Verlag; 2011 [cited 2020 Oct 5]. Available from: https://www. springer.com/gp/book/9781849964166

11. Greene DL, Thompson MC, Gesink DS, Graves SC. Anatomic study of the medial neurovascular structures in relation to calcaneal osteotomy. Foot Ankle Int. $2001 \mathrm{Jul}$; 22(7): 569-71.

12. DiDomenico LA, Anain J, Wargo-Dorsey M. Assessment of Medial and Lateral Neurovascular Structures after Percutaneous Posterior Calcaneal Displacement Osteotomy: A Cadaver Study. J Foot Ankle Surg [Internet]. 2011 Nov 1 [cited 2020 Oct 5]; 50(6): 668-71. Available from: http://www.sciencedirect.com/science/article/pii/ S1067251611003905

13. Havel PE, Ebraheim NA, Clark SE, Jackson WT, DiDio L. Tibial nerve branching in the tarsal tunnel. Foot Ankle. 1988; 9(3): 117-9.

14. Casey D, McConnell T, Parekh S, Tornetta P. Percutaneous pin placement in the medial calcaneus: is anywhere safe? J Orthop Trauma. 2002; 16(1): 26-9.

15. Gamie Z, Donnelly L, Tsiridis E. The 'safe zone' in medial percutaneous calcaneal pin placement. Clin Anat $N$ YN. 2009; 22(4): 523-9. 